\title{
Dayside midlatitude ionospheric response to storm time electric fields: A case study for 7 September 2002
}

\author{
M. David, ${ }^{1}$ J. J. Sojka, ${ }^{1}$ R. W. Schunk, ${ }^{1}$ M. W. Liemohn, ${ }^{2}$ and A. J. Coster ${ }^{3}$ \\ Received 11 July 2011; revised 9 September 2011; accepted 16 September 2011; published 2 December 2011.
}

[1] With the storm of 7-8 September 2002 as a study case, we demonstrate that an ionospheric model driven by a suitable storm time convection electric field can reproduce the $F$ region dayside density enhancements associated with the ionospheric storm positive phase. The ionospheric model in this case is the Utah State University Time Dependent Ionospheric Model (TDIM); the electric field model is the University of Michigan's Hot Electron and Ion Drift Integrator (HEIDI). Extensive ground truth is available throughout the study period from two independent sources: ground-based vertical TEC and ionosonde stations; our simulation results are in good agreement with these observations. We address the question of what is the source of the high-density plasma that is seen during the positive storm phase and show that in this case a magnetospheric electric field with an eastward component that penetrates to midlatitudes increases local production on the dayside to a degree that is sufficient to account for the storm time density increases that have been observed.

Citation: David, M., J. J. Sojka, R. W. Schunk, M. W. Liemohn, and A. J. Coster (2011), Dayside midlatitude ionospheric response to storm time electric fields: A case study for 7 September 2002, J. Geophys. Res., 116, A12302, doi:10.1029/2011JA016988.

\section{Introduction}

[2] Electron density enhancements in the dayside ionosphere are often seen during geomagnetic storms. Foster and Rideout [2005] described the magnitude and extent of these $F$ region enhancements, which may represent a doubling of the $F$ region electron densities as measured by either the Total Electron Content (TEC) or the peak density $(\mathrm{NmF} 2)$. Most often these positive phase features have been reported over the United States; it is not clear whether the American sector is actually favored for their formation, or if this surplus of sightings is due to an observational bias, owing to the relatively high density of GPS TEC receivers in the United States, as well as the high degree of interest in ionospheric irregularities in the U.S. because of the disruptions that may be caused in communications or the Wide Area Augmentation System (WAAS). When seen over the U.S., the enhancement often takes the form of an extended $F$ layer high-density ridge aligned in a northwest direction. Its northern extremity may be the storm enhanced density (SED) feature described by Foster [1993]. Foster et al. [2002], using satellite UV imagery, found that the plasmaspheric "drainage plumes" were on the same magnetic field lines as the $F$ layer density ridge. A study of European

\footnotetext{
${ }^{1}$ Center for Atmospheric and Space Sciences, Utah State University, Logan, Utah, USA.

${ }^{2}$ Department of Atmospheric, Oceanic and Space Sciences, University of Michigan, Ann Arbor, Michigan, USA.

${ }^{3}$ Haystack Observatory, Massachusetts Institute of Technology, Westford, Massachusetts, USA.

Copyright 2011 by the American Geophysical Union. 0148-0227/11/2011JA016988
}

ionosonde data covering nearly a half century was carried out by David and Sojka [2010]; among the findings was that these positive phase enhancements are by no means limited to intense storm periods; in fact, they were often seen to occur during times of very moderate disturbances that followed extended quiet periods. The source of the plasma that constitutes these density increases has been the subject of a good deal of debate during the last decade; a number of mechanisms have been proposed to account for the enhancements. Tanaka and Hirao [1973] demonstrated that an eastward electric field will raise the $F$ layer and thereby increase $\mathrm{NmF} 2$. This lifting of the $F$ layer could also be the result of equatorward thermospheric winds, independent of any electric field. Tsurutani et al. [2004] and Mannucci et al. [2005] showed correlations between enhancements at midlatitudes and equatorial latitudes, leading them to suggest that both vertical and horizontal transport from equatorial regions leads to the enhancements. However, Heelis and Coley [2007] found midlatitude enhancements that were not correlated with equatorial anomaly enhancements. Sobral et al. [1997] discuss large-scale plasma transport at low latitudes during a series of storm periods, while Tsurutani et al. [2008] give a detailed discussion of the dayside ionospheric enhancement at low latitudes during a very intense storm.

[3] Heelis et al. [2009], in a study based on in situ observations from the Defense Meteorological Satellite Program (DMSP), examined a storm period in which the boundaries of the disturbed magnetospheric electric field were seen to have moved equatorward by as much as 15 degrees of latitude. This extended, or "penetrating" electric field was then shown to be capable of producing TEC enhancements on the dayside. With Utah State University's Time Dependent 

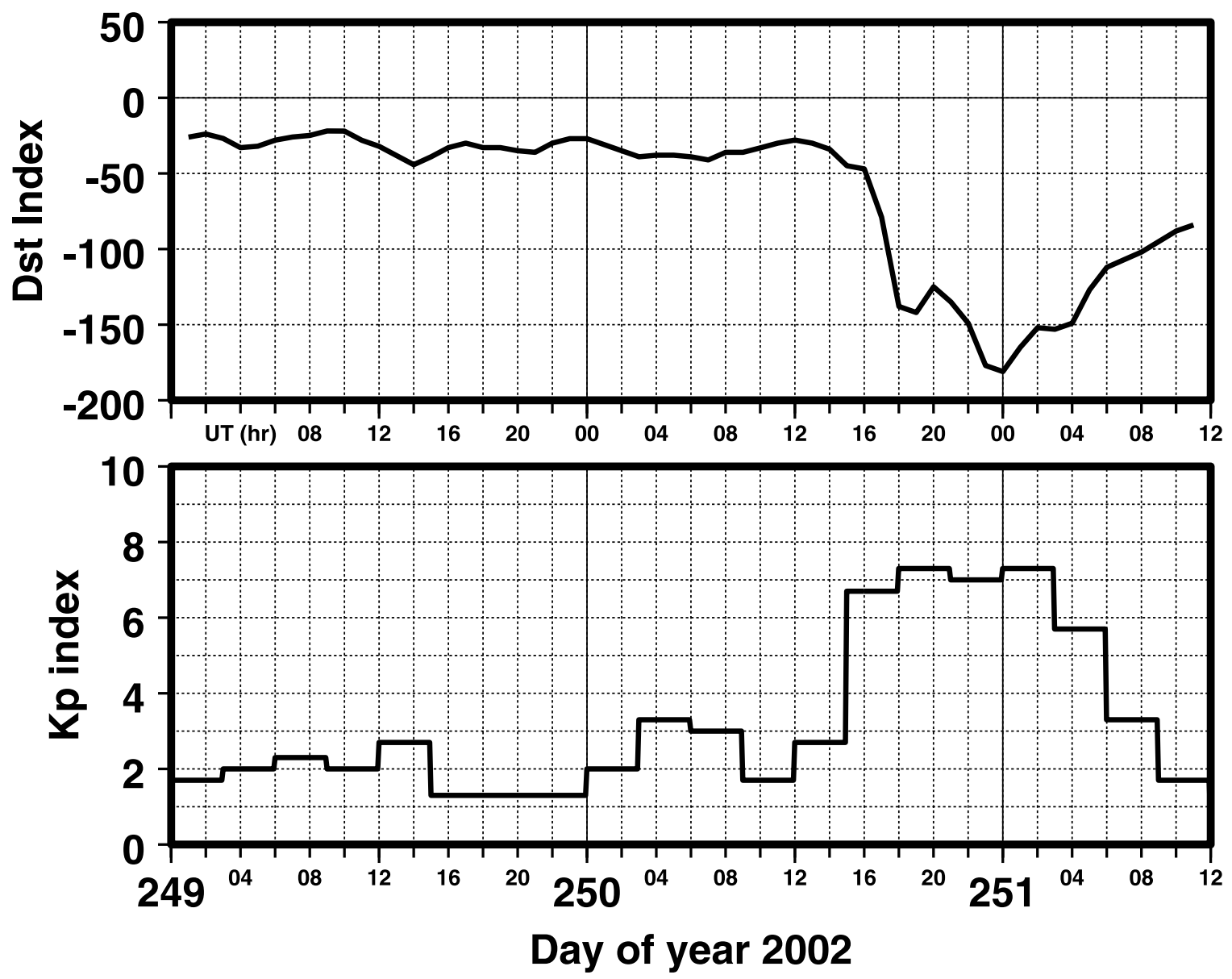

Figure 1. Geomagnetic activity as given by the indices $D s t$ and $K p$ during the $21 / 2$ day study period of 6-8 September 2002. The storm onset occurs about halfway through 7 September (day 250).

Ionospheric Model (TDIM) it was shown that an eastward electric field with a strength of only about $4 \mathrm{mV} / \mathrm{m}$ is sufficient to bring about a doubling of the midlatitude dayside TEC within several hours. Thus Heelis et al.'s [2009] work argued strongly that local production, and not transport, was a key mechanism for the storm time dayside enhancements. David et al. [2010], presented at the AGU Fall Meeting, extended the TDIM model by incorporating convection electric field patterns from the University of Michigan's Hot Electron and Ion Drift Integrator model (HEIDI) (see section 4 of this paper). The storm period of 17 April 2002 was simulated; the result was an extensive and structured dayside midlatitude $F$ region enhancement. However, at that time it was not possible to make comparisons of the modeled result with observations, as the simulation showed the enhancement region to be located over the Atlantic Ocean. In the work reported in this paper we have redone and expanded the study, again using convection patterns from the HEIDI model, this time for the storm period of 8 September 2002 when data from both GPS TEC and ionosonde observations are available for comparison with simulation results.

[4] It is our intention to put to the test, with realistic electric field conditions that were in effect during the storm of 7-8 September 2002, the claims put forward by Heelis et al. [2009] based on a very simple electric field model; namely, that a storm time magnetospheric electric field is (or can be) sufficient to bring about midlatitude dayside TEC enhancements of the magnitude that is observed; and that it is not necessary to suppose that high-density plasma already existing at lower latitudes must be transported northward in order to account for the observed density increases.

\section{The Study Period, 6-8 September 2002}

[5] A geomagnetic storm of moderate intensity set in near 15:00 UT on 7 September 2002 (day 250), reaching a Dst minimum of -180 just after 00:00 UT the following day; the United States east coast is at about $10 \mathrm{~h}$ local time at the storm's onset. The maximum value of the 3-hourly $K p$ index was $7^{+}$. What we refer to as our "study period" includes the quiet day preceding the onset of the storm, that is, $6 \mathrm{Sep}$ tember (day 249), all of day 250, and the first half of day 251. Figure 1 shows how the geomagnetic activity evolved during this period, as indicated by both the 1-hourly Dst index, and the 3-hourly $K p$ index. This storm was chosen as a good study case for several reasons: First, the storm has a well-defined and steep onset following a period of quiet conditions. Second, the timing of the storm's onset is such that positive storm effects are likely to be produced in the American longitude sector (J. J. Sojka et al., A modeling study of the longitudinal dependence of storm time midlatitude dayside TEC enhancements, submitted to Journal of 
Day 2492100 UT
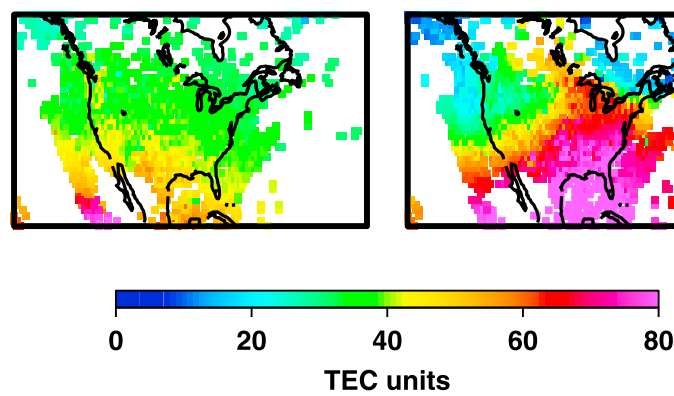

Day 2502100 UT

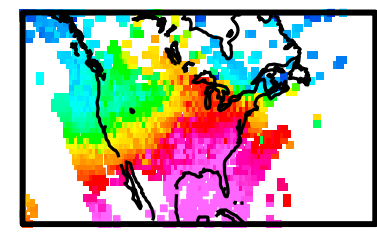

80
Figure 2. Vertical TEC data from GPS over North America (left) at 21:00 UT on 6 September 2002 during quiet conditions and (right) at the same time on 7 September, about $6 \mathrm{~h}$ after the storm onset.

GeophysicalResearch, 2011); this will make for easy comparison with observations, due to the excellent coverage of GPS TEC data over North America. Third, the availability of electric field convection patterns from the University of Michigan's HEIDI model (see section 4). Also, the availability of measurements of the $F$ region peak $\left(f_{o} F_{2}\right)$ from several ionosonde stations in North America (see section 6), for comparison with the model results. Note that this storm has been referred to in the literature [e.g., Zhang et al., 2007] as 8 September 2002; it has been labeled in this way based on the day of occurrence of the Dst minimum. Despite this, our focus in this paper is on 7 September, and the positive storm effects (i.e., $F$ region density enhancements) that occurred in North America on that day. We will not discuss the aftereffects of the storm, e.g., the ionospheric depletions (or negative phase) that are often observed following disturbed conditions.

\section{Observations of TEC During the Study Period}

[6] Global total electron content (TEC) data obtained from the network of world wide GPS receivers [Мапписсі et al., 1998; Coster et al., 2003] are calculated using the MIT Automated Processing of GPS (MAPGPS) software [Rideout and Coster, 2006]. These data are available from the Madrigal database, an open source, web based, distributed database system which provides Web-based data storage, retrieval, search, and visualization freely available to the space science community. The TEC estimates are produced in $1^{\circ} \times 1^{\circ}$ bins of latitude/longitude with 5 min temporal resolution and distributed over those locations where data is available. The errors in the MAPGPS code are tracked throughout the processing, and random and correlated errors are handled separately. This allows optimal estimation of binned measurements using weighted averages and allows error values to be calculated from each binned measurement.

[7] Observations of TEC from the GPS system show large-scale enhancements over the North American continent during the latter half of 7 September 2002 (day 250). Figure 2 shows a comparison of the ionosphere at 21:00 UT on the quiet day preceding the storm (Figure 2, left), and at the same universal time on the following day, about 5 or $6 \mathrm{~h}$ after the storm's onset. In the eastern and southern United States the values of TEC are nearly doubled, increasing from levels of about 40-45 TECU on the previous day, to 80 or more during the storm. Steep density gradients are seen along the northern edge of a "ridge" of high TEC starting in the northeastern U.S., in the Great Lakes region, extending diagonally northwestward up into Canada. Steep gradients such as this are thought to cause much of the disruption that occurs in the Federal Aviation Administration's Wide Area Augmentation System (WAAS) during storms. Observations of the $F$ region peak frequency $\left(f_{o} F_{2}\right)$ from ionosonde stations in the U.S. will be discussed in section 6 .

\section{Electric Field and Ionospheric Models}

\subsection{The HEIDI Electric Field Model}

[8] The Hot Electron and Ion Drift Integrator (HEIDI) model solves the gyration and bounce-averaged kinetic equation for the phase space density of energetic particles on closed field lines [Liemohn et al., 2004, 2006]. Developed at the University of Michigan nearly 20 years ago [e.g., Fok et al., 1993; Jordanova et al., 1996], there are now several versions of this model in active use [e.g., Gamayunov et al., 2009; Zheng et al., 2010; Fok et al., 2010; Jordanova et al., 2010; Liemohn et al., 2010]. The code is not a particletracking model but rather discretizes the kinetic equation with high-resolution fluid dynamics algorithms, solving for the distribution on several thousand velocity space cells at each of several hundred spatial grid cells. The code includes collisionless drifts due to convective and magnetic origin, Coulomb collisional scattering and energy decay, charge exchange, precipitative loss to the upper atmosphere, and flow through the simulation boundaries. It is coupled to the Dynamic Global Core Plasma Model (DGCPM) for the plasmaspheric thermal particle densities [Ober et al., 1997; Liemohn et al., 2004], uses the Rairden et al. [1986] neutral hydrogen geocoronal densities, and a static dipole magnetic field. For these simulations, a self-consistent electric field calculation is used [Ridley and Liemohn, 2002; Liemohn et al., 2004, 2005]. In this setup, the model calculates the hot ion pressures and from this the cross-field magnetospheric current density. Divergences of these currents are computed to yield field-aligned currents into and out of the ionosphere, where they are closed through Pedersen currents assuming a dynamically varying conductance. The resulting ionospheric electric potentials are mapped along the magnetic field lines and used in the convective drift terms for the next time step. This yields a negative feedback process that inhibits further hot ion injection into the inner magnetosphere, forming small-scale structure in the hot ion pressure peak [e.g., Liemohn and Brandt, 2005] and undulations in the nightside plasmapause [e.g., Gallagher et al., 2005].

[9] Our purpose in using the HEIDI model is to drive the TDIM ionospheric model (discussed in section 4.2) with realistic convection electric field patterns that represent the storm period of 7-8 September 2002. Previously we have performed such studies with other convection models, for example SuperDARN as well as magnetospheric hydrodynamic (MHD) models, but a very important difference is that the HEIDI model includes electric field information at midlatitudes, as far equatorward as $30^{\circ}$ magnetic. This is crucial in the present study, as we have shown previously [Heelis et al., 2009; David et al., 2010] that an eastward electric field of small magnitude, as low as $1-5 \mathrm{mV} / \mathrm{m}$, on the dayside at midlatitudes can have a large impact on the 

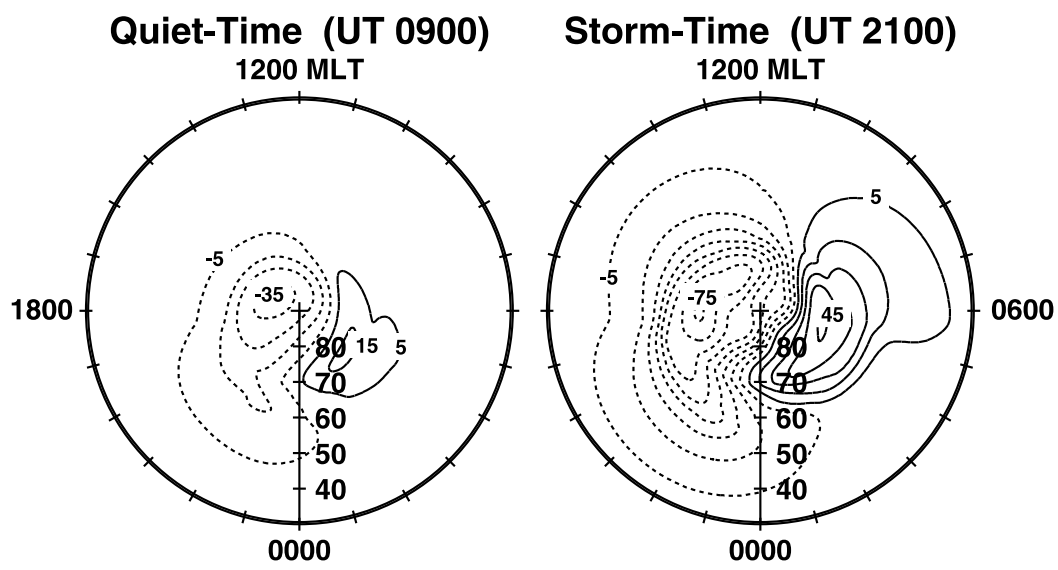

Figure 3. Contours of the HEIDI electric field potential; contour lines are $10 \mathrm{kV}$ apart. Both are taken from 7 September 2002 (left) during quiet conditions at 09:00 UT and (right) during the storm at 21:00 UT.

electron densities in the $F$ region, increasing TEC by as much as a factor of 2 over the course of several hours. In this study we use a series of HEIDI-generated convection electric field patterns spaced $30 \mathrm{~min}$ apart, starting at $0000 \mathrm{UT}$ on day 250 (7 September) and continuing throughout day 251. The patterns extend from the pole down to $30^{\circ}$ magnetic latitude, covering all longitudes. In Figure 3 we show two HEIDI patterns from the series, both for day 250; at left, 09:00 UT, before the storm has begun; and at right, 21:00 UT, about 5 or $6 \mathrm{~h}$ after the onset. The equipotential contours are spaced $10 \mathrm{kV}$ apart. At left, for the quiet time, a count of contour lines reveals a cross-polar cap potential drop of about $60 \mathrm{kV}$; for the storm time pattern at right the drop is $130 \mathrm{kV}$. These numbers are consistent with the relation between the polar cap potential drop and the $K p$ index, $\Phi=20+14 \times K p$ [Heppner, 1973; Kivelson, 1976]. At 09:00 UT the 3-hourly $K p$ value has just changed from 3 to $2-$; for 3 , the above formula gives $\Phi=62$, while at 21:00 UT, with $K p=7^{+}, \Phi=$ 122. It can be seen in Figure 3 that the electric field has expanded to midlatitudes during the disturbed time. In order to gauge the importance of the small-magnitude "residual" electric field that penetrates to midlatitudes, we have run the TDIM model to follow plasma trajectories for three cases and plotted them in Figure 4: case $a$, pure corotation; case $b$, the quiet time HEIDI electric field pattern shown in Figure 3 (left); case $c$, the storm time pattern in Figure 3 (right). The eastward component of the electric field, which even in case $c$ does not exceed $2.5 \mathrm{mV} / \mathrm{m}$, is sufficient to drive the plasma toward the pole across several degrees of latitude. This northward movement of the plasma is all-important, as it is this motion that induces an upward ion drift, owing to the inclination of the magnetic field lines. In case $c$, this upward ion drift has a magnitude of about $20 \mathrm{~m} / \mathrm{s}$; it will be shown later in this paper that this is sufficient to bring about a large increase in $F$ region densities. This mechanism for producing dayside storm time enhancements was discussed at length by Heelis et al. [2009].

\subsection{TDIM}

[10] The TDIM (Time Dependent Ionospheric Model) was initially developed as a midlatitude, multi-ion model by Schunk and Walker [1973] and subsequently extended to include high-latitude effects due to convection electric fields and particle precipitation by Schunk et al. [1975, 1976]. Vertical columns (or "tubes") of plasma are followed as they move in response to $\mathbf{E} \times \mathbf{B}$, as described by Sojka et al. [1981a, 1981b]. The system is Lagrangian, meaning that ion diffusion does not occur between neighboring plasma columns; all horizontal motion of ions and electrons is driven by $\mathbf{E} \times \mathbf{B}$, and each plasma column moves as a unit. A rigorous consideration of the plasma energy balance is included in the calculation of ion and electron temperatures [Schunk and Sojka, 1982; Schunk et al., 1986]. The theoretical development of the TDIM is described by Schunk [1988], while comparisons with observations are discussed by Sojka [1989]. In this study we use the NRLMSISE-00 model [Picone et al., 2002] to specify the neutral atmosphere within the TDIM. The model as configured for this study does not allow for any lifting of the thermosphere due to drag when the ionosphere is lifted by an electric field. Any such raising of the neutral gas would be minor compared to the height by which the $F$ layer is raised in the case studied here. To represent solar conditions during this

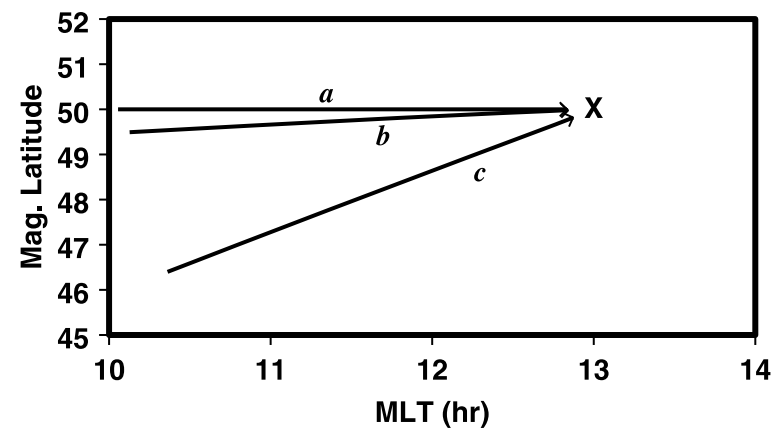

Figure 4. Three $\mathbf{E} \times \mathbf{B}$ trajectory paths leading to the same location at $50^{\circ}$ magnetic latitude, 13:00 MLT. Case $a$ is pure corotation, case $b$ is driven by the quiet time HEIDI convection electric field pattern shown in Figure 3 (left), and case $c$ is driven by the storm time pattern in Figure 3 (right). Unlike cases $a$ and $b$, in case $c$ the plasma is moved poleward through several degrees of latitude during the $3 \mathrm{~h}$ period; this poleward motion induces an upward ion drift of about $20 \mathrm{~m} / \mathrm{s}$. 


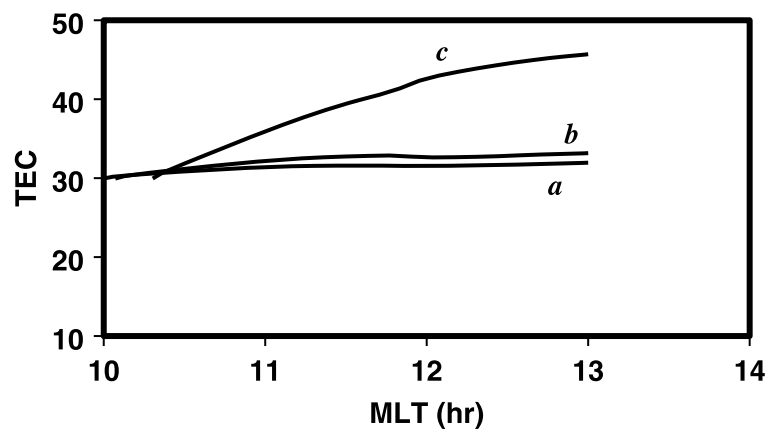

Figure 5. Vertical TEC values from a TDIM simulation for the three trajectory paths shown in Figure 4. Owing to the upward ion drift induced by the poleward convection in case $c$, the $F$ region electron densities are significantly enhanced.

period an F10.7 index of 180 is used. A specification of the thermospheric wind is needed; here we use a simple wind pattern which is set to zero on the dayside, and on the nightside runs in an antisunward direction, with speeds up to $200 \mathrm{~m} / \mathrm{s}$. A dayside neutral wind can have a large impact upon the TEC values [see Sojka et al., 2005]; therefore in this study we use a model which has zero dayside wind to avoid confusion as to how much of the effect is due to the neutral wind, and how much to the electric field. The geoeffectiveness of a neutral wind in producing dayside TEC enhancements during a storm is the focus of a forthcoming study. When running the TDIM outside of the time period for which HEIDI-generated convection patterns are available, we have used the "A" pattern of Heppner and Maynard's [1987] model, with adjustments made for the expansion of the convection region according to the value of the $K p$ index. In section 4.1 we discussed the upward ion drift that is induced by the poleward or northward motion of plasma on the dayside. We have run the TDIM for the three test cases that were shown in Figure 4 in order to assess the ionospheric effect of this upward drift; the results are plotted in Figure 5. These are dayside midlatitude plasma columns moving under the influence of a magnetospheric electric field (plus corotation) for $3 \mathrm{~h}$. Cases $a$ and $b$, for pure corotation and a quiet time HEIDI convection pattern, respectively, show a slight increase in TEC during the $3 \mathrm{~h}$ period; note that a gradual increase is to be expected, since the plasma is in sunlight the entire time. Case $c$, however, which is driven by the storm time convection electric field pattern in Figure 3 (right), and which has a continual upward ion drift of about $20 \mathrm{~m} / \mathrm{s}$, increases from 30 to 48 TECU during the $3 \mathrm{~h}$ period. As discussed in detail by Heelis et al. [2009], this increase occurs because of the $F$ layer plasma being lifted upward out of the main recombination region, while ion production continues to occur due to solar EUV exposure. This lifting of the dayside $F$ layer is the key mechanism for creating the storm time enhancements in the TDIM simulations presented in this paper.

\section{Ionospheric Model Simulations of the Storm Period}

[11] The TDIM ionospheric model, driven by the series of HEIDI-generated convection electric field patterns, has been run to create simulations of the ionosphere in the northern hemisphere from the pole to $30^{\circ}$ magnetic latitude, producing "snapshots" of the ionosphere spaced 30 min apart throughout the study period. In this section we focus on the simulation results for vertical Total Electron Content over North America. Figure 6 shows the model runs at 21:00 UT on the quiet day (Figure 6, left) and at the same universal time on the day of the storm (Figure 6, right). These two plots should be compared with the two plots of GPS TEC observations in Figure 2. In Figures 2 and 6, we see that for the quiet day (Figure 6, left dials) the dynamic range of TEC and the decreasing poleward gradient are very similar in both the observations and the simulation. During the storm's initial phase, at 21:00 UT day 250 (Figure 6, right), the GPS data shows that TEC is increased by about a factor of 2 over much of the United States, the exception being the northwestern region. The model run also shows an increase in TEC by about a factor of 2, even in the northwestern U.S. Of much interest in Figure 2 (right) is the TEC morphology along a northwestward line that passes through the Great Lakes region. This is a "ridge" of high-density plasma which has a steeply declining gradient to the north; it begins out beyond the east coast of the U.S., and extends diagonally well up into Canada. This appears to be the feature that Foster [1993] has labeled the storm enhanced density, or SED. Notice that it is entirely absent on the quiet day. This feature is of particular interest, because it is thought to be steep gradients in TEC, rather than large values of TEC itself, that are responsible for most of the disruptions of the WAAS system during geomagnetic storms. A look at Figure 6 shows that this observed feature has been reproduced quite accurately by the TDIM/HEIDI model. The model runs likewise show no trace of this feature on the quiet day. The question may be asked, would the storm time ionosphere be simulated reasonably well without the HEIDI-generated convection patterns, using instead the Heppner-Maynard statistical patterns adjusted for the changing values of $K p$ ? The answer is that a plot of TEC from such a model run (not shown as a figure in this paper) bears little resemblance to the output of a run done with the HEIDI patterns (or to the observations). It cannot be expected that any statistical convection pattern will closely match the actual conditions of any storm period, since each storm is different, and the comparative rarity of intense storms makes for a small sample set upon which a statistical pattern can be based. Therefore

\section{Day 2492100 UT}
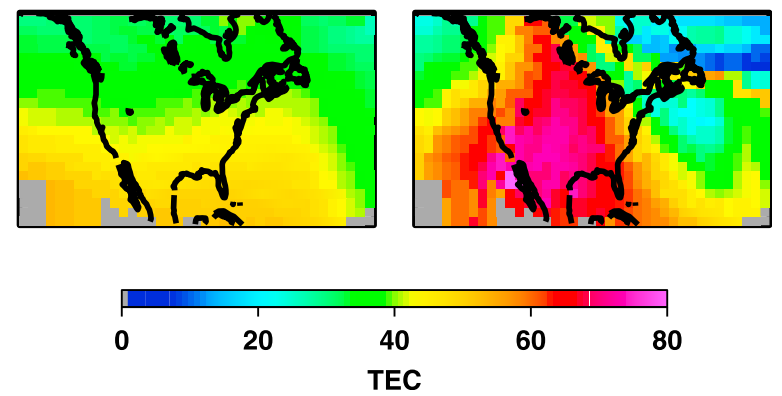

Figure 6. Vertical TEC from TDIM simulations at (left) 21:00 UT on 6 September and (right) 21:00 UT on 7 September 2002. These are to be compared with the GPS TEC observations shown in Figure 2. 

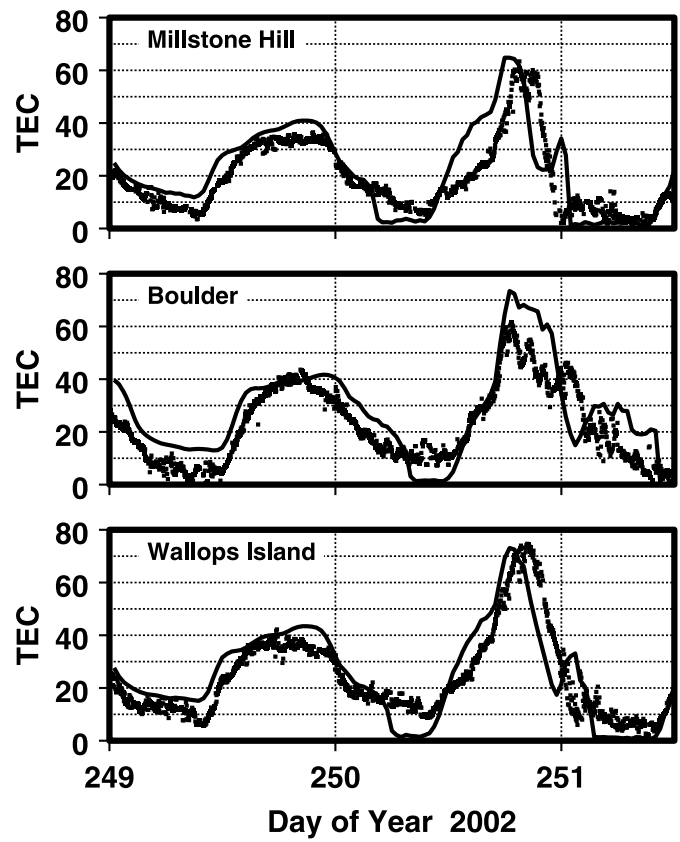

Figure 7. TEC observations (symbols) and simulations (solid curves) during the $21 / 2$ day study period at three different locations: Millstone Hill $\left(42.6^{\circ} \mathrm{N}, 288.5^{\circ} \mathrm{E}\right)$, Boulder $\left(40^{\circ} \mathrm{N}, 254.7^{\circ} \mathrm{E}\right)$, and Wallops Island $\left(37.9^{\circ} \mathrm{N}, 284.5^{\circ} \mathrm{E}\right)$.

we expect that when modeling the ionosphere during a storm period, it will be necessary to use as a driver a physics-based convection electric field model with settings specific for the storm period in question.

\section{Comparison of the Model With Ground Station Data}

[12] Using the Space Physics Interactive Data Base (SPIDR) we were able to collect ionosonde observations of the $F$ layer peak frequency $f_{o} F_{2}$ for three stations in the U.S. during our study period: Boulder $\left(40^{\circ} \mathrm{N}, 254.7^{\circ} \mathrm{E}\right)$, Millstone Hill $\left(42.6^{\circ} \mathrm{N}, 288.5^{\circ} \mathrm{E}\right)$, and Wallops Island $\left(37.9^{\circ} \mathrm{N}\right.$, $\left.284.5^{\circ} \mathrm{E}\right)$. These three stations all saw significant $F$ region density enhancements on 7 September 2002. There are GPS receivers located at or near these stations, allowing us to compare the model output TEC with observations; we show these comparisons first, in Figure 7. In determining the TEC data value at a station's location, all available TEC values within $100 \mathrm{~km}$ of the location are used. It is apparent that the model/data match for TEC is very good at all three locations, notwithstanding an apparent time shift of 2-3 $\mathrm{h}$ which is noticeable in Figures 7 (top) and 7 (middle). The comparison of the $F$ region peak frequency value $f_{o} F_{2}$ is also good, though somewhat less so; it is shown in Figure 8. On the quiet day (249), the diurnal variations of $f_{o} F_{2}$ for both the observations and simulations are very similar. This diurnal pattern changes on the storm day; observations and simulations reflect a similar change.

\section{Tracing the History of the High-Density Plasma}

[13] Where does the storm time high-density plasma come from? There are two main schools of thought: (1) existing high-density plasma is transported from lower latitudes [see Tsurutani et al., 2004; Mannucci et al., 2005]; and (2) that it is the result of local production; this does not necessarily mean an increase in the local production rate, it may be the result of the same amount of local production, but with decreased rate of loss due to recombination. In work by Heelis et al. [2009] we argued for the second explanation; this section of the paper is devoted to tracing back in time the dayside high-density feature in the HEIDI-driven TDIM model simulations for 7 September 2002 to see exactly where it came from. When running an ionospheric model, it is easy to find out where any plasma feature has come from: we recreate its past history by following the $\mathbf{E} \times \mathbf{B}$ trajectories of plasma columns (or "tubes") with time running backward. In Figure 9 we show the result of doing this with a column which, at 21:00 UT on 7 September 2002 (about $6 \mathrm{~h}$ after the storm onset), is located in the midst of the dayside enhancement region. Figure 9 has eight dial plots, each a "snapshot" of TEC at one universal time, in magnetic coordinates from the pole to $30^{\circ}$ latitude. Magnetic local time (MLT) increases in the counterclockwise direction, with midnight at the bottom and noon at the top of each dial. The progress of one particular plasma column is followed throughout the series, indicated by a marker in each dial. The movement of this column in the magnetic frame is determined by the series of HEIDI-generated convection patterns (plus corotation). Close visual inspection reveals that, in addition to advancing $1 \mathrm{~h}$ of MLT for each hour of universal time due to corotation, from about 16:00 UT onward the column moves northward (i.e., inward, toward the pole) by perhaps 1 to 1.5 degrees of latitude per hour. As mentioned earlier, and explained fully by Heelis et al. [2009], it is this poleward motion of dayside plasma that is responsible for the lifting of the $F$ layer and the consequent buildup of electrons. A detailed history of the plasma column through
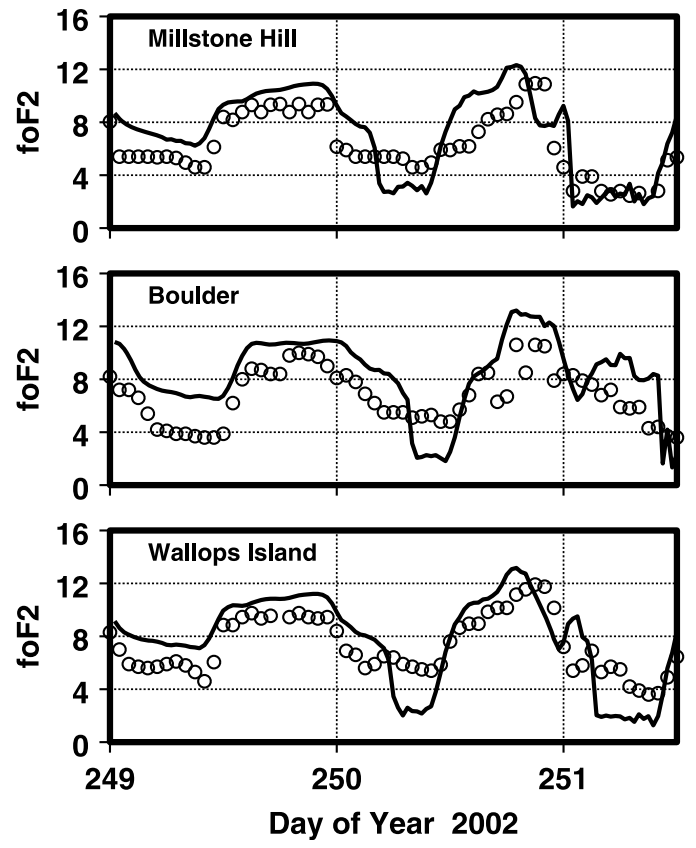

Figure 8. Ionosonde observations of $f_{o} F_{2}$ (symbols) and simulations (solid curves) during the $21 / 2$ day study period at the same three locations shown in Figure 7. 

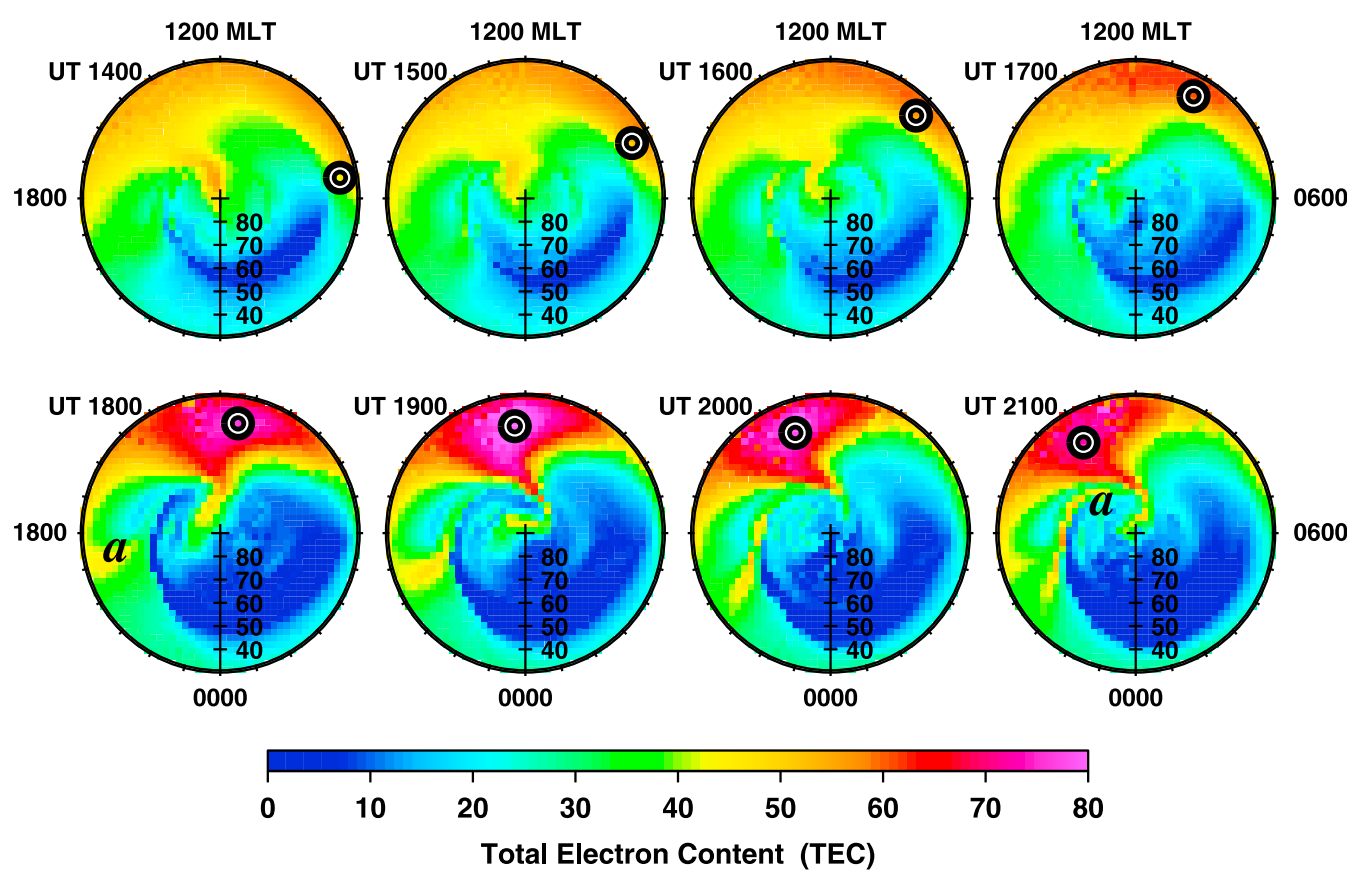

Figure 9. Eight dial plots of TEC from TDIM simulations, from 14:00 to 21:00 UT on 7 September 2002, driven by HEIDI convection electric field patterns. The progress of an individual plasma column (or "tube") is followed throughout the period; its location is marked by a circle in each dial plot, as described in section 7. The letter " $a$ " that appears in two plots in Figure 9 (bottom) is used to indicate the presence of a density enhancement feature, discussed at the end of section 7 .

this $7 \mathrm{~h}$ period is given in Figure 10. The altitude profile between 100 and $800 \mathrm{~km}$ is shown, with the logarithm of electron density $(\mathrm{Ne})$ color coded from $10^{5.25}$ to $10^{6.50}$ electrons per $\mathrm{cm}^{3}$. At each integer hour the column's location is marked in the dials of Figure 9. Since this is a single column, its history is self-contained; that is to say, no plasma enters or leaves it, and all changes in the electron content are due to local processes of production and recombination, or diffusion up and down the column. (The TDIM as configured for the present study does not allow for any plasma
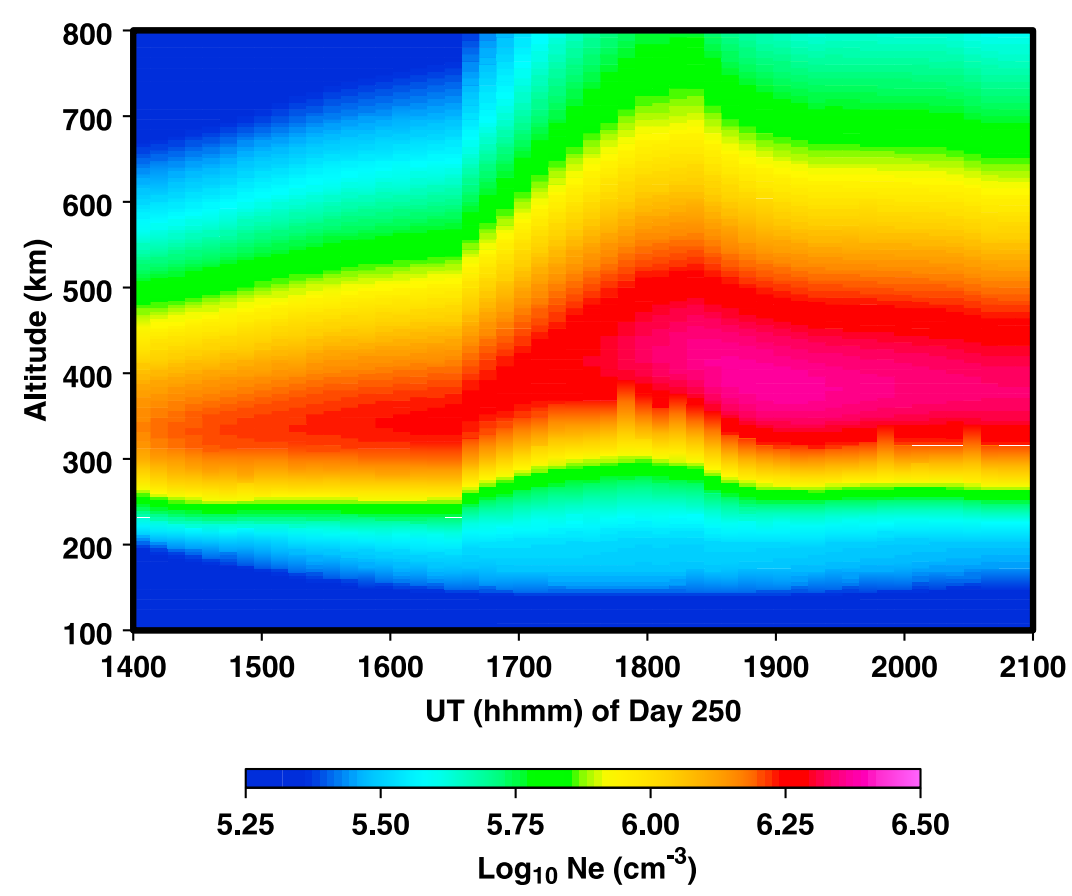

Figure 10. Color-coded altitude profile of the electron density $\mathrm{Ne}$ for the time period along the plasma column trajectory path indicated in the dial plots of Figure 9, discussed in section 7. Note that the height of the $F$ layer has increased, reaching a maximum shortly after 18:00 UT. 
flux from higher altitudes.) Figure 10 shows that, until the occurrence of the storm onset the altitude profile has a maximum $\mathrm{Ne}(\mathrm{NmF} 2)$ of about $10^{6.1}$, or $1.25 \times 10^{6}$ (yellow to light red in color), with the height of the peak (hmF2) being about $330 \mathrm{~km}$; then the $F$ layer is lifted upward over the course of several hours, with $\mathrm{hmF} 2$ rising to $400 \mathrm{~km}$ or more, and the peak density $\mathrm{NmF} 2$ coming up to about $10^{6.4}$, or $2.5 \times 10^{6}$ per $\mathrm{cm}^{3}$. The density enhancement occurs without the transport of any plasma from lower latitudes. The lifting of the $F$ layer does not increase the amount of local production, but it does markedly decrease the rate at which ions are lost due to recombination; this process is sufficient to bring about an increase in TEC by a factor of 2 .

[14] Referring back to Figure 9, the HEIDI convection patterns have given rise to an interesting feature of enhanced density (marked with the letter " $a$ " in two dials of Figure 9 (bottom) which begins to form in the dusk sector several hours after the storm onset, and then elongates and stretches toward higher latitudes during the next few hours. That such a feature exists here is very interesting, and it will be the object of follow-up work as more HEIDI-generated convection patterns become available to us for other storm periods. It is not possible here to find this feature within the set of observations, as it is located over the Atlantic Ocean where data is not available. In any case, it is clearly separate from, and minor compared to, the dayside region of TEC enhancement.

\section{Summary}

[15] We have modeled the dayside ionospheric enhancements of the storm period of 7-8 September 2002. The model runs show good agreement with both GPS TEC observations and ionosonde station data. In this case, Utah State University's physics-based TDIM ionospheric model was driven by convection electric field patterns from the University of Michigan's HEIDI model, which is based on the physics of the inner magnetosphere-plasmasphere-ionosphere coupling. It was shown that the high-density plasma of the dayside enhancement in the TDIM simulation was entirely the result of local production, due to an upward ion drift caused by the magnetospheric electric field expanded to midlatitudes during the storm period.

[16] Heelis et al. [2009] had used a very simple electric field model with a makeshift expansion to midlatitudes, and claimed that its effect was sufficient to cause large-scale TEC enhancements on the dayside, and that it was therefore unnecessary to hypothesize that high-density plasma from lower latitudes was being transported northward. In the numerical experiment reported in this paper we have put that claim to the test using a much more sophisticated representation of a storm time electric field specific to 7-8 September 2002; the comparison of the modeling results with GPS and ionosonde data strongly supports the claim alluded to above, both as regards the magnitude of the enhancement, and its spatial and temporal distribution.

[17] Acknowledgments. This research was supported by NSF grant AGS-0962544 to Utah State University; NSF grant ATM-0856093 to the Massachusetts Institute of Technology; and NASA grants NNX08AQ15G and NNX09AF45G and NSF grant ATM-0802705 to the University of Michigan.
[18] Robert Lysak thanks the reviewers for their assistance in evaluating this paper.

\section{References}

Coster, A. J., J. C. Foster, and P. J. Erickson (2003), Monitoring the ionosphere with GPS, GPS World, 14(5), 42-45.

David, M., and J. J. Sojka (2010), Single-day dayside density enhancements over Europe: A survey of a half-century of ionosonde data, J. Geophys. Res., 115, A12311, doi:10.1029/2010JA015711.

David, M., J. J. Sojka, R. W. Schunk, and M. W. Liemohn (2010), Midlatitude dayside ionospheric response to storm-time electric fields, Abstract SA34A-08, presented at 2010 Fall Meeting, AGU, San Francisco, Calif., 13-17 Dec.

Fok, M.-C., J. U. Kozyra, A. F. Nagy, C. E. Rasmussen, and G. V. Khazanov (1993), Decay of equatorial ring current ions and associated aeronomical consequences, J. Geophys. Res., 98(A11), 19,381-19,393, doi:10.1029/ 93JA01848

Fok, M.-C., N. Buzulukova, S.-H. Chen, P. W. Valek, J. Goldstein, and D. J. McComas (2010), Simulation and TWINS observations of the 22 July 2009 storm, J. Geophys. Res., 115, A12231, doi:10.1029/ 2010JA015443.

Foster, J. C. (1993), Storm-time plasma transport at middle and high latitudes, J. Geophys. Res., 98, 1675-1689, doi:10.1029/92JA02032.

Foster, J. C., and W. Rideout (2005), Midlatitude TEC enhancements during the October 2003 superstorm, Geophys. Res. Lett., 32, L12S04, doi:10.1029/2004GL021719.

Foster, J. C., A. J. Coster, P. J. Erikson, J. Goldstein, and F. J. Rich (2002), Ionospheric signatures of plasmspheric tails, Geophys. Res. Lett., 29(13), 1623, doi:10.1029/2002GL015067.

Gallagher, D. L., M. L. Adrian, and M. W. Liemohn (2005), The origin and evolution of deep plasmaspheric notches, J. Geophys. Res., 110, A09201, doi:10.1029/2004JA010906.

Gamayunov, K. V., G. V. Khazanov, M. W. Liemohn, M.-C. Fok, and A. J. Ridley (2009), Self-consistent model of magnetospheric electric field, ring current, plasmasphere, and electromagnetic ion cyclotron waves: Initial results, J. Geophys. Res., 114, A03221, doi:10.1029/ 2008JA013597.

Heelis, R. A., and W. R. Coley (2007), Variations in the low- and middlelatitude topside ion concentration observed by DMSP during superstorm events, J. Geophys. Res., 112, A08310, doi:10.1029/2007JA012326.

Heelis, R. A., J. J. Sojka, M. David, and R. W. Schunk (2009), Storm time density enhancements in the middle-latitude dayside ionosphere, J. Geophys. Res., 114, A03315, doi:10.1029/2008JA013690.

Heppner, J. P. (1973), High latitude electric fields and the modulations related to interplanetary magnetic field parameters, Radio Sci., 8 , 933-948, doi:10.1029/RS008i011p00933.

Heppner, J. P., and N. C. Maynard (1987), Empirical high-latitude electric field models, J. Geophys. Res., 92, 4467-4489, doi:10.1029/ JA092iA05p04467.

Jordanova, V. K., L. M. Kistler, J. U. Kozyra, G. V. Khazanov, and A. F. Nagy (1996), Collisional losses of ring current ions, J. Geophys. Res., 101(A1), 111-126, doi:10.1029/95JA02000.

Jordanova, V. K., S. Zaharia, and D. T. Welling (2010), Comparative study of ring current development using empirical, dipolar, and self-consistent magnetic field simulations, J. Geophys. Res., 115, A00J11, doi:10.1029/ 2010JA015671.

Kivelson, M. G. (1976), Magnetospheric electric fields and their variation with geomagnetic activity, Rev. Geophys., 14, 189-197, doi:10.1029/ RG014i002p00189.

Liemohn, M. W., and P. C. Brandt (2005), Small-scale structure in the stormtime ring current, in Inner Magnetosphere Interactions: New Perspectives From Imaging, Geophys. Monogr. Ser., vol. 159, edited by J. L. Burch, M. Schulz, and H. Spence, pp. 167-177, AGU, Washington, D. C., doi:10.1029/159GM13.

Liemohn, M. W., A. J. Ridley, D. L. Gallagher, D. M. Ober, and J. U. Kozyra (2004), Dependence of plasmaspheric morphology on the electric field description during the recovery phase of the 17 April 2002 magnetic storm, J. Geophys. Res., 109, A03209, doi:10.1029/2003JA010304.

Liemohn, M. W., A. J. Ridley, P. C. Brandt, D. L. Gallagher, J. U. Kozyra, D. G. Mitchell, E. C. Roelof, and R. DeMajistre (2005), Parametric analysis of nightside conductance effects on inner magnetospheric dynamics for the 17 April 2002 storm, J. Geophys. Res., 110, A12S22, doi:10.1029/2005JA011109.

Liemohn, M. W., A. J. Ridley, J. U. Kozyra, D. L. Gallagher, M. F. Thomsen, M. G. Henderson, M. H. Denton, P. C. Brandt, and J. Goldstein (2006), Analyzing electric field morphology through data-model comparisons of the Geospace Environment Modeling Inner Magnetosphere/Storm Assess- 
ment Challenge events, J. Geophys. Res., 111, A11S11, doi:10.1029/ 2006JA011700.

Liemohn, M. W., M. Jazowski, J. U. Kozyra, N. Ganushkina, M. F. Thomsen, and J. E. Borovsky (2010), CIR versus CME drivers of the ring current during intense magnetic storms, Proc. R. Soc. A, 466(2123), 3305-3328, doi:10.1098/rspa.2010.0075.

Mannucci, A. J., B. D. Wilson, D. N. Yuan, C. H. Ho, U. J. Lindqwister, and T. F. Runge (1998), A global mapping technique for GPS-derived ionospheric total electron content measurements, Radio Sci., 33(3), 565-582, doi:10.1029/97RS02707.

Mannucci, A. J., B. T. Tsurutani, B. A. Iijima, A. Komjathy, A. Saito, W. D. Gonzalez, F. L. Guarnieri, J. U. Kozyra, and R. Skoug (2005), Dayside global ionospheric response to the major interplanetary events of 29-30 October 2003 "Halloween Storms," Geophys. Res. Lett., 32, L12S02, doi:10.1029/2004GL021467.

Ober, D. M., J. L. Horwitz, and D. L. Gallagher (1997), Formation of density troughs embedded in the outer plasmasphere by subauroral ion drift events, J. Geophys. Res., 102, 14,595-14,602, doi:10.1029/97JA01046.

Picone, J. M., A. E. Hedin, D. P. Drob, and A. C. Aikin (2002), NRLMSISE-00 empirical model of the atmosphere: Statistical comparisons and scientific issues, J. Geophys. Res., 107(A12), 1468, doi:10.1029/ 2002JA009430.

Rairden, R. L., L. A. Frank, and J. D. Craven (1986), Geocoronal imaging with Dynamics Explorer, J. Geophys. Res., 91, 13,613-13,630, doi:10.1029/JA091iA12p13613.

Rideout, W., and A. Coster (2006), Automated GPS processing for global total electron content data, GPS Solutions, 10, 219-228, doi:10.1007/ s10291-006-0029-5.

Ridley, A. J., and M. W. Liemohn (2002), A model-derived description of the penetration electric field, J. Geophys. Res., 107(A8), 1151, doi:10.1029/2001JA000051

Schunk, R. W. (1988), A mathematical model of the middle and highlatitude ionosphere, Pure Appl. Geophys., 127, 255-303, doi:10.1007/ BF00879813.

Schunk, R. W., and J. J. Sojka (1982), Ion temperature variation in the daytime high-latitude $F$ region, J. Geophys. Res., 87, 5169-5183, doi:10.1029/JA087iA07p05169.

Schunk, R. W., and J. C. G. Walker (1973), Theoretical ion densities in the lower ionosphere, Planet Space Sci., 21, 1875-1896, doi:10.1016/00320633(73)90118-9.

Schunk, R. W., W. J. Raitt, and P. M. Banks (1975), Effect of electric fields on the daytime high-latitude $E$ and $F$ regions, J. Geophys. Res., 80 3121-3130, doi:10.1029/JA080i022p03121.

Schunk, R. W., P. M. Banks, and W. J. Raitt (1976), Effect of electric fields and other processes upon the nighttime high-latitude $F$ layer, J. Geophys. Res., 81, 3271-3282, doi:10.1029/JA081i019p03271.
Schunk, R. W., J. J. Sojka, and M. D. Bowline (1986), Theoretical study of the electron temperature in the high-latitude ionosphere for solar maximum and winter conditions, J. Geophys. Res., 91, 12,041-12,054, doi:10.1029/JA091iA11p12041.

Sobral, J. H. A., M. A. Abdu, W. D. Gonzalez, B. T. Tsurutani, and I. S. Batista (1997), Effects of intense storms and substorms on the equatorial ionosphere/thermosphere system in the American sector from ground based and satellite data, J. Geophys. Res., 102, 14,305-14,313, doi:10.1029/97JA00576.

Sojka, J. J. (1989), Global scale, physical models of the $F$ region ionosphere, Rev. Geophys., 27, 371-403, doi:10.1029/RG027i003p00371.

Sojka, J. J., W. J. Raitt, and R. W. Schunk (1981a), A theoretical study of the high-latitude winter $F$ region at solar minimum for low magnetic activity, J. Geophys. Res., 86, 609-621, doi:10.1029/JA086iA02p00609.

Sojka, J. J., W. J. Raitt, and R. W. Schunk (1981b), Theoretical predictions for ion composition in the high-latitude winter $F$ region for solar minimum and low magnetic activity, J. Geophys. Res., 86, 2206-2216, doi:10.1029/JA086iA04p02206.

Sojka, J. J., M. David, R. W. Schunk, and A. P. van Eyken (2005), Polar $F$-layer model-observation comparisons: A neutral wind surprise, Ann. Geophys., 23, 191-199, doi:10.5194/angeo-23-191-2005.

Tanaka, T., and K. Hirao (1973), Effects of an electric field on the dynamic behavior of the ionosphere and its application to the storm time disturbance of the F-layer, J. Atmos. Terr. Phys., 35, 1443-1452, doi:10.1016/00219169(73)90147-5

Tsurutani, B., et al. (2004), Global dayside ionospheric uplift and enhancement associated with interplanetary electric fields, J. Geophys. Res., 109, A08302, doi:10.1029/2003JA010342.

Tsurutani, B. T., et al. (2008), Prompt penetration electric fields (PPEFs) and their ionospheric effects during the great magnetic storm of 30 31 October 2003, J. Geophys. Res., 113, A05311, doi:10.1029/ 2007JA012879.

Zhang, J., et al. (2007), Solar and interplanetary sources of major geomagnetic storms (Dst $\leq-100 \mathrm{nT})$ during 1996-2005, J. Geophys. Res., 112, A10102, doi:10.1029/2007JA012321.

Zheng, Y., A. T. Y. Lui, and M.-C. Fok (2010), Effects of plasma sheet properties on storm-time ring current, J. Geophys. Res., 115, A08220, doi:10.1029/2009JA014806.

A. J. Coster, Haystack Observatory, Massachusetts Institute of Technology, Westford, MA 01886-1229, USA.

M. David, R. W. Schunk, and J. J. Sojka, Center for Atmospheric and Space Sciences, Utah State University, Logan, UT 84322-4405, USA. (michael.david@aggiemail.usu.edu)

M. W. Liemohn, Department of Atmospheric, Oceanic and Space Sciences, University of Michigan, Ann Arbor, MI 48109-2143, USA. 